Of course, the door is not closed on the final recommendations for high blood cholesterol evaluation and treatment. Further recommendations on the clinical importance of HDL cholesterol in the generation of coronary heart disease will be forthcoming by the adult treatment panel. While the NCEP coordinating committee is expected to update its recommendations approximately every 3 years, the current objective is to see that every adult in the United States has a cholesterol determination. To that end, the National Heart, Lung, and Blood Institute has made these standard guidelines available to the clinician so that we can prescribe treatment-diet, weight reduction, and drug therapy when indicated-based on a relatively sound, scientific foundation.

W.H. VOSS, DO, FACOI

AOA Representative to the

NCEP Coordinating Committee

National Heart/Blood/Lung Institute

1. Frick MH, Elo, Hasapa K, et al: Helsinki heart study: Primary prevention trial with gemfibrozil in middle-aged men with dyslipidemia. $N$ Engl J Med 1987;317:1237-1245.

\section{JAOA provides ongoing AIDS education for physicians}

In the JAOA this month, Dr. Leonard Calabrese and Dennis Kelley, BA, RN, discuss how physicians play a critical role in the prevention of the acquired immunodeficiency syndrome (AIDS) by helping patients understand how to reduce the risk of contracting this dreaded disease. Their insights come from first-hand experience in dealing with AIDS patients. The central theme remains the same: Emphasize physician education first, then patient education.

Various strategies for the prevention of sexual transmission of HIV are presented and their practicality and efficiency are discussed. Among them, the intravenous drug abuse population presents a formidable challenge to the successful control of AIDS. The homosexual community has pulled together to fight this disease, but the ability of this group as well as health-care education and other professionals to affect disease transmission by the intravenous drug abusers is of serious concern. Creative programs must be developed to control AIDS among these patients.

Because serological testing plays a substantial screening and diagnostic role in AIDS, all osteopathic physicians must familiarize themselves with this tool. Additionally, developing a pre- and posttest educational and counseling program becomes an essential component of any serological testing program. Dr. Calabrese carefully reviews these issues and offers a discerning approach to accomplish this delicate and at times threatening, emotional process.

Our AIDS educational effort, presented monthly in the JAOA methodically covers, in an up-to-date fashion, the essential information health care providers need to fight this disease. As osteopathic physicians, we must spend time reviewing this information in order to provide the best possible care for our patients.

GILBERT E. D'ALONZO, JR, DO

Contributing Editor, JAOA

AIDS Task force, AOA leading health care company, has excellent private
lospital practice opportunities for qualified physicians in such specialties as:

\begin{tabular}{|c|c|}
\hline $\begin{array}{l}\text { Anesthesiology } \\
\text { Family Practice } \\
\text { Internal Medicine } \\
\text { Oncology } \\
\text { Otolaryngology }\end{array}$ & $\begin{array}{l}\text { Psychiatry } \\
\text { Cardiology } \\
\text { General Surgery } \\
\text { Obstetrics \& Gynecology } \\
\text { Orthopedic Surgery }\end{array}$ \\
\hline
\end{tabular}

For more information about our wide range of physician practice opportunities contact HCA

Physician Recruitment Services, One Park Plaza,

P.O. Box 550, Suite 302, Nashville, TN 37202-0550.

Or call 1-800-251-2561 or 1-800-342-2110 in

Tennesseo. 